\title{
Editorial
}

\section{Smoking as a Target for Prevention of Diabetes}

\author{
Ye Seul Yang, Tae Seo Sohn \\ Department of Internal Medicine, Uijeongbu St. Mary's Hospital, College of Medicine, The Catholic University of Korea, Seoul, Korea
}

Diabetes is characterized by a variable degree of impaired insulin secretion and insulin resistance, driven by both genetic and environmental factors. To date, several genetic and environmental factors have been studied to understand the pathophysiology of diabetes [1]. Even though much progress has been made in genetics, the fundamental basis of diabetes management is managing the environmental factors. However, health behaviors in diabetes patients are commonly not satisfied in Korea [2]. Further, the Korean prevalence of diabetes in 2030 is projected to increase two-fold compared with levels of 2013 to 2014 when considering the contribution of environmental risk factors [3].

On the other hand, the ultimate purpose of glucose control is to prevent micro- and macrovascular complications. As the leading cause of death in patients with diabetes is cardiovascular disease (CVD), optimal management of CVD risk factors like smoking, physical inactivity, high blood pressure, and dyslipidemia, as well as managing glucose level is critical for preventing diabetic complications. Since publication of the results of the Framingham Heart Study, these risk factors have become the target for patient management, and the rates of cardiovascular complications and mortality due to CVD in diabetes patients have declined worldwide, as well as in Korean [4].

Beyond treating diabetes and CVD risk factors, effort is moving to prevent development of diabetes, and lifestyle modification showed positive effect in several long-term observational studies $[5,6]$. In this regard, modifiable factors including smoking, high blood pressure, obesity, and dyslipidemia are considered risk factors of diabetes, and many risk scoring systems use these variables to calculate the risk for developing di- abetes $[7,8]$. However, smoking is not emphasized as a modifiable factor for preventing diabetes compared to its impact as a cardiovascular risk factor. American Diabetes Association guidelines mentioned that smoking 'may' increase the risk of diabetes [9].

In the article entitled, "Association between cigarette smoking and new-onset diabetes mellitus in 78,212 Koreans using self-reported questionnaire and urine cotinine," Kim et al. [10] assessed cigarette smoking status by urine cotinine level, as well as a self-reported questionnaire in a prospective cohort and showed an association between smoking and new-onset diabetes in Korean individuals. The association showed a dosedependent pattern; a higher daily amount and longer duration of smoking increased diabetes risk ( $P$ for trends $<0.05$ ). Interestingly, self-reported former smoking did not show an increased risk of incident diabetes in this study, and it would be better if body weight change could be considered. Also, since the association increased in a dose-dependent manner in current smokers, it would be more desirable to analyze the association in former smokers, specifically regarding the amount and duration of former smoking.

There have been consistent results about the association between smoking and incident diabetes risk [11-14]. However, in a real-world clinical setting, the physician usually encounters limitations in encouragement of lifestyle modification, especially smoking cessation, for preventing diabetes. One of the challenges is that patients often worry about weight gain and withdrawal effects after quitting smoking. Substantial weight gain within 6 years of smoking cessation was associated with increased short-term risk of type 2 diabetes mellitus, according
Corresponding author: Tae Seo Sohn (iD https://orcid.org/0000-0002-5135-3290 Department of Internal Medicine, Uijeongbu St. Mary's Hospital, College of Medicine, The Catholic University of Korea, 271 Cheonbo-ro, Uijeongbu 11765, Korea E-mail: imsts@catholic.ac.kr
This is an Open Access article distributed under the terms of the Creative Commons Attribution Non-Commercial License (https://creativecommons.org/licenses/by-nc/4.0/) which permits unrestricted non-commercial use, distribution, and reproduction in any medium, provided the original work is properly cited. 
to a longitudinal cohort study [15], although sustained smoking cessation was not. However, the increased risk was shown only in recent quitters who showed greater than $5.1 \mathrm{~kg}$ weight gain, and the hazard ratios for death from CVD decreased in all recent quitters regardless of weight gain compared with current smokers. Therefore, it is important that physicians help hinder patients from gaining weight after quitting smoking and should have some strategies for maximizing the health benefits of smoking cessation. The first step of such interventions is to improve diet quality and increase physical activities [16].

Another issue is that physicians usually assess patient smoking status and dose only through patient self-reporting. In this aspect, an approach with urine cotinine level will be useful in real-world settings. In this study, urinary cotinine level alone showed significant association (relative risk, 1.04; 95\% confidence interval, 1.01 to 1.06) with increased risk of diabetes [10]. Moreover, urinary cotinine is highly sensitive, non-invasive, inexpensive, and easy to check using once-daily semiquantitative immunoassay test strips [17-19]. If further study could provide the recommendable target levels of biomarkers of smoking status, like urine cotinine level, to prevent diabetes risk, it is expected that physicians would have more objective methods to assess patient smoking status, including secondhand and e-cigarette smokers. Moreover, they could educate patients about smoking cessation based on more objective assessment and measurable targets.

As shown in several studies, including this study [10], lifestyle patterns and metabolic syndrome factors share a similar tendency; former smokers or never-smokers have more favorable lifestyle patterns and better cardiometabolic profiles-including blood pressure, glucose, glycosylated hemoglobin, and high-density lipoprotein cholesterol than current smokers. These other competing risk factors may affect the results of the analysis and make it difficult to determine whether smoking is an independent and causal factor of the consequence.

We assert that more prospective clinical studies with intervention are needed to reach a concrete conclusion of whether smoking is a causal factor of incident diabetes, and thus smoking cessation will be valuable as a target for its prevention. A randomized controlled clinical trial, the community-based Korean Diabetes Prevention Study (C-KDPS), is ongoing to prevent type 2 diabetes mellitus by intensive lifestyle modification using a web-based program [20]. Quitting smoking is one of the major goals of the C-KDPS lifestyle intervention program. As more relevant evidence is accumulated in further studies, nationwide and individual pharmaceutical and lifestyle intervention will be regarded more critical. Considering the association between smoking and diabetes risk as well as cardiovascular risk, it is time that more attention be paid to these issues.

\section{CONFLICTS OF INTEREST}

No potential conflict of interest relevant to this article was reported.

\section{REFERENCES}

1. Kwak SH, Park KS. Pathophysiology of type 2 diabetes in Koreans. Endocrinol Metab (Seoul) 2018;33:9-16.

2. Kim BY, Won JC, Lee JH, Kim HS, Park JH, Ha KH, Won KC, Kim DJ, Park KS. Diabetes fact sheets in Korea, 2018: an appraisal of current status. Diabetes Metab J 2019;43:487-94.

3. Baik I. Projection of diabetes prevalence in Korean adults for the year 2030 using risk factors identified from national data. Diabetes Metab J 2019;43:90-6.

4. Korean Diabetes Association. Diabetes \& Complications in Korea [Internet]. Available from: https://www.diabetes.or.kr/ pro/news/admin.php?category $=$ A\&code $=$ admin\&number $=17$ 88\&mode=view (updated 2019 Oct 10).

5. Li G, Zhang P, Wang J, An Y, Gong Q, Gregg EW, Yang W, Zhang B, Shuai Y, Hong J, Engelgau MM, Li H, Roglic G, Hu Y, Bennett PH. Cardiovascular mortality, all-cause mortality, and diabetes incidence after lifestyle intervention for people with impaired glucose tolerance in the Da Qing Diabetes Prevention Study: a 23-year follow-up study. Lancet Diabetes Endocrinol 2014;2:474-80.

6. Diabetes Prevention Program Research Group. Long-term effects of lifestyle intervention or metformin on diabetes development and microvascular complications over 15-year followup: the Diabetes Prevention Program Outcomes Study. Lancet Diabetes Endocrinol 2015;3:866-75.

7. Lee YH, Bang H, Kim HC, Kim HM, Park SW, Kim DJ. A simple screening score for diabetes for the Korean population: development, validation, and comparison with other scores. Diabetes Care 2012;35:1723-30.

8. Ha KH, Lee YH, Song SO, Lee JW, Kim DW, Cho KH, Kim DJ. Development and validation of the Korean diabetes risk score: a 10-year national cohort study. Diabetes Metab J 2018;42:40214.

9. American Diabetes Association. 3. Prevention or delay of type 
2 diabetes: standards of medical care in diabetes. 2020. Diabetes Care 2020;43(Suppl 1):S32-6.

10. Kim JH, Seo DC, Kim BJ, Kang JG, Lee SJ, Lee SH, Kim BS, Kang JH. Association between cigarette smoking and new-onset diabetes mellitus in 78,212 Koreans using self-reported questionnaire and urine cotinine. Diabetes Metab J 2020;44: 426-38.

11. Hur NW, Kim HC, Nam CM, Jee SH, Lee HC, Suh I. Smoking cessation and risk of type 2 diabetes mellitus: Korea Medical Insurance Corporation Study. Eur J Cardiovasc Prev Rehabil 2007;14:244-9.

12. Jee SH, Foong AW, Hur NW, Samet JM. Smoking and risk for diabetes incidence and mortality in Korean men and women. Diabetes Care 2010;33:2567-72.

13. Pan A, Wang Y, Talaei M, Hu FB, Wu T. Relation of active, passive, and quitting smoking with incident type 2 diabetes: a systematic review and meta-analysis. Lancet Diabetes Endocrinol 2015;3:958-67.

14. Akter S, Goto A, Mizoue T. Smoking and the risk of type 2 diabetes in Japan: a systematic review and meta-analysis. J Epidemiol 2017;27:553-61.

15. Hu Y, Zong G, Liu G, Wang M, Rosner B, Pan A, Willett WC, Manson JE, Hu FB, Sun Q. Smoking cessation, weight change, type 2 diabetes, and mortality. N Engl J Med 2018;379:623-32.

16. Farley AC, Hajek P, Lycett D, Aveyard P. Interventions for preventing weight gain after smoking cessation. Cochrane Database Syst Rev 2012;1:CD006219.

17. Acosta M, Buchhalter A, Breland A, Hamilton D, Eissenberg T. Urine cotinine as an index of smoking status in smokers during 96-hr abstinence: comparison between gas chromatography/mass spectrometry and immunoassay test strips. Nicotine Tob Res 2004;6:615-20.

18. Schepis TS, Duhig AM, Liss T, McFetridge A, Wu R, Cavallo DA, Dahl T, Jatlow P, Krishnan-Sarin S. Contingency management for smoking cessation: enhancing feasibility through use of immunoassay test strips measuring cotinine. Nicotine Tob Res 2008;10:1495-501.

19. Benowitz NL, Bernert JT, Foulds J, Hecht SS, Jacob P, Jarvis MJ, Joseph A, Oncken C, Piper ME. Biochemical verification of tobacco use and abstinence: 2019 update. Nicotine Tob Res 2020; 22:1086-97.

20. Cha SA, Lim SY, Kim KR, Lee EY, Kang B, Choi YH, Yoon KH, Ahn YB, Lee JH, Ko SH. Community-based randomized controlled trial of diabetes prevention study for high-risk individuals of type 2 diabetes: lifestyle intervention using web-based system. BMC Public Health 2017;17:387. 